\title{
One last kick at the can
}

\section{B Pless}

\section{The high number of deaths of children from injuries in many wealthy countries is a political embarrassment}

$\mathrm{n}$ the past I have commented on what should be viewed by our political mas-

ters as a source of great embarrassment. I am referring to the appalling results reported by Unicef's Innocenti Research Center year after year for some countries. I do so again following the arrival of Report Card 7, Child poverty in perspective: an overview of child well-being in rich countries. ${ }^{1}$ The sub-title of the report is "A comprehensive assessment of the lives and well-being of children and adolescents in the economically advanced nations." Only included are data from OECD countries but that should be enough to make many of us sit up and take notice.

In particular, I call attention (not to you, dear reader, but to the most senior politician you voted for) to the chart that shows the ranking of Canada, Australia, New Zealand, and the USA with respect to deaths from "accidents and injuries per 100000 under 19 years" (Figure 2.3). Canada ranks 13th, Australia is 17th, the US is 22nd, and New Zealand is 24th. Need I say more?
The time is long overdue for a concerted national effort in each of these countries, one led by well-funded national centers. It is ironic perhaps that it was in the first volume of this journal that Berfenstam described the program responsible for Sweden's astonishing success. ${ }^{2}$ At that time the program had been in existence for 40 years. Now, a half a century later, these four countries, alongside others of equal wealth, have still not caught up. Nor will they until they take the injury problem as seriously as they do other more popular diseases.

Injury Prevention 2007;13:362.

doi: 10.1136/ip.2007.017426

Correspondence to: Professor I B Pless, Editor; barry.pless@mcgill.ca

\section{REFERENCES}

1 Unicef. Child poverty in perspective: an overview of child well-being in rich countries. Innocenti Report Card 7. Florence: UNICEF Innocenti Research Centre, 2007.

2 Berfenstam R. Sweden's pioneering child accident programme: 40 years later. Inj Prev 1995;1:68-9.

\section{A correction: how I fixed my mistake}

\section{$P$ Cummings}

\section{Estimates of deaths of bicyclists attributable to not wearing a helmet are corrected, with explanation}

I n 2006, colleagues and I published a study of US traffic deaths during 19822001. ${ }^{1}$ There were 858741 deaths, and we estimated that (a) 366607 could be attributed to alcohol use, (b) 259239 to not wearing a seat belt, (c) 31377 to lack of an air bag, (d) 12095 to not wearing a motorcycle helmet, and (e) 10552 to not wearing a bicycle helmet. Jointly, these factors accounted for 528105 deaths, $61 \%$ of all the traffic deaths; this joint total was less than the sum of the five counts because some deaths could be assigned to more than one factor.

To estimate the counts above, we used attributable fractions. ${ }^{2-5}$ Imagine a hypothetical series of 100 unhelmeted motorcycle drivers who died; how many of those deaths would have been prevented if all the drivers had worn a helmet? The risk of death in a motorcycle crash has been reported to be greater for an unhelmeted motorcycle driver than for an otherwise similar driver who was helmeted: risk ratio (RR) $1.54 .^{6}$ The fraction of motorcycle driver deaths that can be attributed to not wearing a helmet is $(\mathrm{RR}-1) / \mathrm{RR}=(1.54-1) / 1.54=$ 0.35 . So, among the hypothetical 100 unhelmeted motorcycle drivers who died, $100 \times 0.35=35$ deaths were due to not wearing a helmet.

A few months after the study of traffic deaths was published, ${ }^{1}$ I realized that I had made an error. To estimate deaths attributable to alcohol, no seat belt, no air bag, and no motorcycle helmet, I correctly used risk ratios for the outcome of death. But to estimate deaths of bicyclists resulting from not wearing a helmet, I used a risk ratio for brain injury, not death, when a helmet was not worn. ${ }^{7}$ Not all bicyclist deaths result from a brain injury. Whereas helmets may prevent some deaths from brain injury, it seems doubtful that helmets can prevent lethal chest or abdominal injuries. In retrospect, my mistake seems obvious; I cannot understand how I made it.

To fix my error, I searched for published estimates of the proportion of bicyclist deaths in vehicle collisions that were due to brain injury alone. Two studies were too small to be of use. ${ }^{8}$ One study of 4812 bicyclist deaths attributed $62 \%$ to a brain injury, but that estimate did not remove deaths that involved both a brain injury and other potentially lethal injuries..$^{10}$
Table 1 Corrected table 1 from Cummings et al': traffic crash deaths attributed to each risk factor, USA, 1982-2001

\begin{tabular}{|c|c|c|c|c|c|}
\hline \multirow[b]{2}{*}{ Risk factor } & \multirow[b]{2}{*}{ Affected population } & \multirow{2}{*}{$\begin{array}{l}\text { All deaths in } \\
\text { affected } \\
\text { population } \\
\text { (count) }\end{array}$} & \multicolumn{3}{|c|}{$\begin{array}{l}\text { Deaths attributed to each } \\
\text { risk factor }\end{array}$} \\
\hline & & & Count & Rate & \%* \\
\hline $\begin{array}{l}\text { No bicycle helmet } \\
\text { No bicycle helmet } \\
\text { All } 5 \text { risk factors } \\
\text { All } 5 \text { risk factors }\end{array}$ & $\begin{array}{l}\text { Bicycle riders } \\
\text { Bicycle riders } \\
\text { All traffic deaths } \\
\text { All traffic deaths }\end{array}$ & $\begin{array}{l}16473 \\
16473 \\
858741 \\
858741\end{array}$ & $\begin{array}{l}10552 \\
4854 \\
528105 \\
524099\end{array}$ & $\begin{array}{l}0.21 \\
0.09 \\
10.30 \\
10.22\end{array}$ & $\begin{array}{l}64 \\
29 \\
61 \\
61\end{array}$ \\
\hline
\end{tabular}

Rates per 100000 person-years. Table is abridged to show only estimates that involved bicycle helmets Corrected estimates, in bold font, based on corrected attributable fraction for no use of a bicycle helmet. $* \%=100 \times$ attributed deaths/deaths in affected population. 


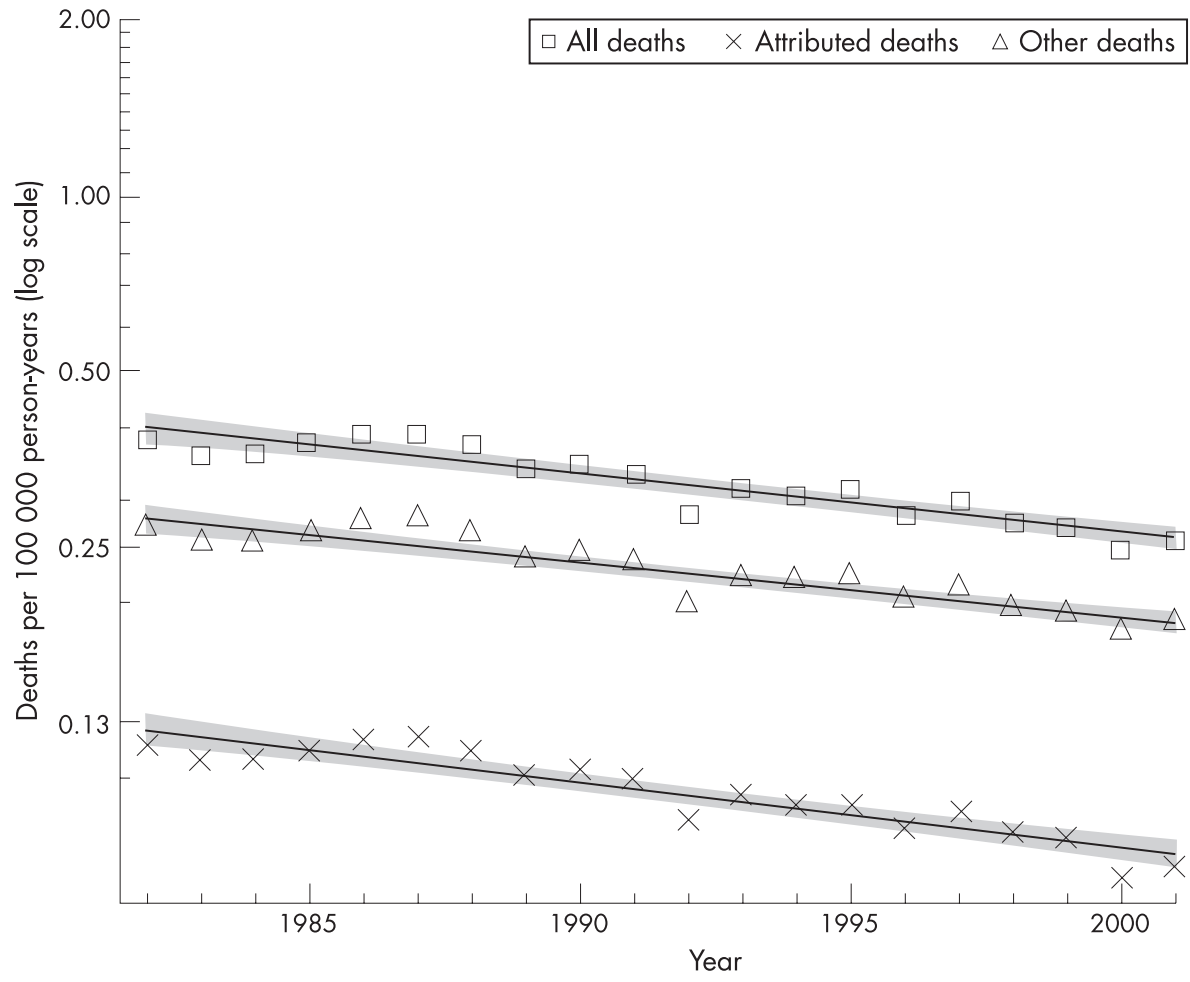

Figure 1 Corrected version of part of fig 3 from Cummings et af': trends in death rates for bicycle riders. The top line shows the observed rates and the fitted line for all crash deaths of bicycle riders. Also shown are the observed rates and fitted lines for deaths attributed to no bicycle helmet and for other deaths not attributed to that factor. The $y$-axis uses a log scale so that convergence or divergence of changes in rates can be easily judged. Pointwise $95 \%$ confidence intervals are shaded.

I therefore used US multiple cause of death public-use data for the years 19911994. ${ }^{11}$ Among the 3015 bicyclists who died in a motor-vehicle crash, 1727 (57\%) had at least one code for head or brain injury, and 1058 (35\%) had a code for head or brain injury and no code for other serious

injury. The first of these proportions may approximate the upper limit for deaths due to a brain injury, whereas the second may estimate the lower limit. I averaged these to estimate the proportion of deaths that might have been avoided had there been no brain injury: $(0.57+0.35) / 2=0.46$. I

Table 2 Corrected table 3 from Cummings et al': rates (per 100000 person-years) and change in rates, for all deaths, deaths attributed to each risk factor, and other deaths not attributed to each risk factor ${ }^{*}$

\begin{tabular}{|c|c|c|c|c|c|}
\hline \multirow[b]{2}{*}{ Risk factor } & \multicolumn{5}{|l|}{ Rates } \\
\hline & $1982 \dagger$ & $2001 \dagger$ & Differenceł & Change (\%) & $95 \% \mathrm{Cl}$ \\
\hline \multicolumn{6}{|l|}{ No bicycle helmet } \\
\hline Attributed deaths & 0.26 & 0.16 & -0.10 & -39 & -45 to -33 \\
\hline Attributed deaths & 0.12 & 0.07 & -0.05 & -39 & -45 to -33 \\
\hline Other deaths & 0.14 & 0.10 & -0.04 & -28 & -32 to -23 \\
\hline Other deaths & 0.28 & 0.18 & -0.09 & -33 & -38 to -28 \\
\hline \multicolumn{6}{|l|}{ All 5 risk factors } \\
\hline All deaths & 19.57 & 14.39 & -5.18 & -26 & -30 to -23 \\
\hline Attributed deaths & 14.22 & 7.36 & -6.85 & -48 & -51 to -45 \\
\hline Attributed deaths & 14.12 & 7.30 & -6.81 & -48 & -51 to -45 \\
\hline Other deaths & 5.64 & 7.26 & +1.62 & +29 & +18 to +41 \\
\hline Other deaths & 5.74 & 7.32 & +1.58 & +28 & +17 to +39 \\
\hline
\end{tabular}

Table is abridged to show only estimates that involved bicycle helmets. Corrected estimates, in bold font, are based on corrected attributable fraction for no use of a bicycle helmet.

*Not all persons were considered exposed to all risk factors. For example, only vehicle occupants (not motorcyclists) were considered to be at risk for not wearing a seat belt, and only motorcycle riders were considered to be potential wearers of motorcycle helmets. Death rates attributed to each risk factor alone sum to more than rates attributed to all five risk factors, as some deaths can be attributed to more than one factor.

tRates for 1982 and 2001 are from the fitted models.

$\ddagger$ Rate difference $=2001$ rate -1982 rate

- Rate change $=(2001$ rate -1982 rate $) /(1982$ rate $)$. multiplied the attributable fraction of brain injuries that might be prevented by not wearing a bicycle helmet $(0.65)$ by the proportion of bicyclist deaths that may be due to brain injury alone (0.46), to obtain a corrected attributable fraction for bicyclist deaths due to not wearing a helmet: $0.65 \times$ $0.46=0.30$.

My next chore was to re-estimate all the statistics in the 2006 paper $^{1}$ that required the bicycle helmet attributable fraction. This looked daunting: there were over 11500 files which filled 14 gigabytes of hard-drive space, including hundreds of files to create or transform variables, carry out multiple imputation, and analyze the data. Fortunately, I was helped by some of my work habits. ${ }^{12}$ For a research project, I always create variables in one set of files, and perform analyses in another set. So I only needed to redo some of the analyses. And I always keep a computerized index of the analysis files, including a list of the electronic files of commands used to create each table and figure. I made copies of those command files, corrected the attributable fractions, and ran the statistical commands again. In a few days the work was done.

Corrected estimates are shown in abridged versions of tables 1 and 3. Part of fig 3 was also revised. Text on page 152 of the published paper ${ }^{1}$ reported deaths prevented by increased use of bicycle helmets: the published estimate was 239, the corrected estimate 73 . The published estimate of deaths prevented by changes in all five factors was 293 898, the corrected estimate 283412 . I also corrected Appendix 4, which is available online from Injury Prevention.

When correcting a paper it is customary for authors to express regret for their errors. I feel regret for several reasons. Firstly, I do research in the hope that some of what I do may actually be useful in preventing future injuries; erroneous estimates cannot serve that purpose well. Secondly, I devote effort to finding and removing errors from my work before publication; it is discouraging and humbling when errors occur despite my precautions. However, I take some comfort from corrections; thanks to the cooperation of journals, it is possible to undo mistakes. I practiced medicine before starting a career in research; it is far easier to fix mistakes in research than in medical care.

Injury Prevention 2007;13:362-364. doi: 10.1136/ip.2007.017293

Correspondence to: $\operatorname{Dr} P$ Cummings, 250 Grandview Drive, Bishop, CA 93514, USA; peterc@u.washington.edu

Accepted 1 October 2007

Competing interests: None. 


\section{REFERENCES}

1 Cummings $\mathbf{P}$, Rivara FP, Olson CM, et al. Changes in traffic crash mortality rates attributed to use of alcohol, or lack of a seat belt, air bag, motorcycle helmet, or bicycle helmet, United States, 19822001. Inj Prev 2006;12:148-54.

2 MacMahon B, Trichopoulos D. Epidemiology: principles and methods, 2nd edn. Boston: Little, Brown, 1996:291-9.

3 Benichou J. Attributable risk. In: Gail MH, Benichou J, eds. Encyclopedia of epidemiologic methods. New York: John Wiley \& Sons, 2000:50-63

4 Rothman KJ. Epidemiology: an introduction. New York: Oxford University Press, 2002:12-13, 53-5.
5 Koepsell TD, Weiss NS. Epidemiologic methods: studying the occurrence of illness. New York: Oxford University Press, 2003:196-201.

6 Norvell DC, Cummings P. Association of helmet use with death in motorcycle crashes: a matched-pair cohort study. Am J Epidemiol 2002;156:483-7.

7 Thompson DC, Rivara FP, Thompson RS. Effectiveness of bicycle helmets in preventing head injuries: a case-control study. JAMA 1996;276: 1968-73.

8 Corner JP, Whitney CW, O'Rourke N, et al. Motorcycle and bicycle protective helmets: requirements resulting from a post crash study and experimental research. Report CR 55. Canberra, Australia: Federal Office of Road Safety, 1987.
9 Sage MD, Cairns FJ, Koelmeyer TD, et al. Fatal injuries to bicycle riders in Auckland. N Z Med J 1985;98:1073-4.

10 Sacks JJ, Holmgreen P, Smith SM, et al. Bicycleassociated head injuries and deaths in the United States from 1984 through 1988. How many are preventable? JAMA 1991;266:3016-18.

11 Public Use Data File Documentation: Multiple Cause of Death for ICD-9 1994 Data. Hyattsville, MD: National Center for Health Statistics, 1996.

12 Cummings P. Organizing a project analysis: some suggestions. http://depts.washington.edu/hiprc/ resources/pdf/

anallec\%2Orevised\%20Jan\%2026\%202006.pdf (revised 26 Jan 2006; accessed 24 Sep 2007).

\section{Using a sledgehammer to crack a walnut: the modern management of concussion}

\section{P McCrory}

\section{Sports concussion is still poorly understood and therefore difficult to prevent and manage}

$\mathrm{T}$ he recent newspaper reports from the USA suggesting the need for legislation to improve the management of sports concussion is to be encouraged, although the scientific basis for these recommendations is probably incorrect and raises a number of disturbing issues. ${ }^{1}$

How has this situation arisen? There is no doubt that our pathophysiological understanding of sports concussion is incomplete and our management, at best, empirical. Recent expert consensus statements have led to some degree of uniformity of approach and a move away from anecdotal management; however, it is a moot point as to how widespread these consensus views have been adopted by athletes. ${ }^{23}$

Studies performed in rugby football suggest that, although coaches and parents have a good understanding of the nature and risks of concussion, the athletes themselves seem not to appreciate the potential consequences and, as a result, tend to under-report the injury to medical staff. ${ }^{4}$ How much of that reflects a lack of athlete-specific education, peer pressure to continue, or simply a function of the immature adolescent brain to understand risk behavior is unclear. Studies from other sports similarly demonstrate this under-reporting bias. ${ }^{5}$

The risks of concussion are not entirely clear. Given the frequency of the injury in sport and the tendency for athletes to continue to play while symptomatic, it is surprising that problems are not encountered more often. This tends to suggest that most injuries are both mild and benign. The caveat here is that the problems may not be picked up by medical staff, as they can affect scholastic performance in young athletes or result in difficulties in the workplace, which are outcomes not usually sought in most sporting situations.

One of the concerns related to the acute concussion injury is the fear of the socalled second-impact syndrome. This fear largely drives the various anecdotal concussion grading scales in the USA and is the principal basis for the arbitrary exclusion periods after injury. ${ }^{6}$ Whether this phenomenon of brain swelling is a consequence of recurrent concussion, as suggested, or an extremely rare (and possibly genetically based) sequela of traumatic brain injury in young athletes remains unresolved.

There is an increasing body of work using sophisticated research tools such as functional MR brain scanning ${ }^{8}$ and neurophysiological studies ${ }^{9}$ to objectively quantify functional changes within the brains of acutely concussed patients. Despite this, our empirical consensus beliefs suggest that that the underlying injury is non-structural in nature and that the symptoms and signs are manifest through cell membrane changes rather than destruction of the cells themselves. To some degree the debate between those who believe in a structural injury and those who support a functional injury has been going on for more than 300 years without definitive resolution. ${ }^{10}$

Recent reports have suggested that a long-term consequence of sports concussion may be chronic traumatic encephalopathy (or punch drunk syndrome), which adds a new dimension to the debate. ${ }^{11}{ }^{12}$ Extensive correspondence has accompanied these case reports, which have criticized both the diagnostic methodology used in the studies and the clinical detail provided in the published reports. ${ }^{13}$ At this time, that debate remains an open question.

Other studies, without neuropathological evidence, have also suggested that recurrent concussion is associated with both depressive symptoms and late life cognitive impairment. ${ }^{14}$ Although an interesting association is evident, it is obvious that a number of statistical confounders are likely to be important, given the lifestyle and alcohol/drug use that is common in professional sport. It is also surprising given that no association was noted in this particular athlete population between concussion and Alzheimer's disease given that head injury is a wellstudied and recognized risk factor for this condition. Clearly, the issue of potential long-term problems has been highlighted as one of concern and raises issues as to whether this might be prevented.

One of the difficulties in these studies is that other sports that have far higher rates of sports concussion (eg, Australian football, rugby) and are equally well studied do not show the same short or long term problems that seem to be evident in the reports from American football research. Similarly, so-called second-impact syndrome is unknown outside the USA despite being specifically sought. ${ }^{7}$ The reasons for these differences are unclear, but may reflect the different nature of injuries in US sportsmen (eg helmeted athletes, head contact with artificial turf surfaces and/or protective equipment) or other unrelated confounders (eg, use of ergogenic supplements or anabolic steroids). 